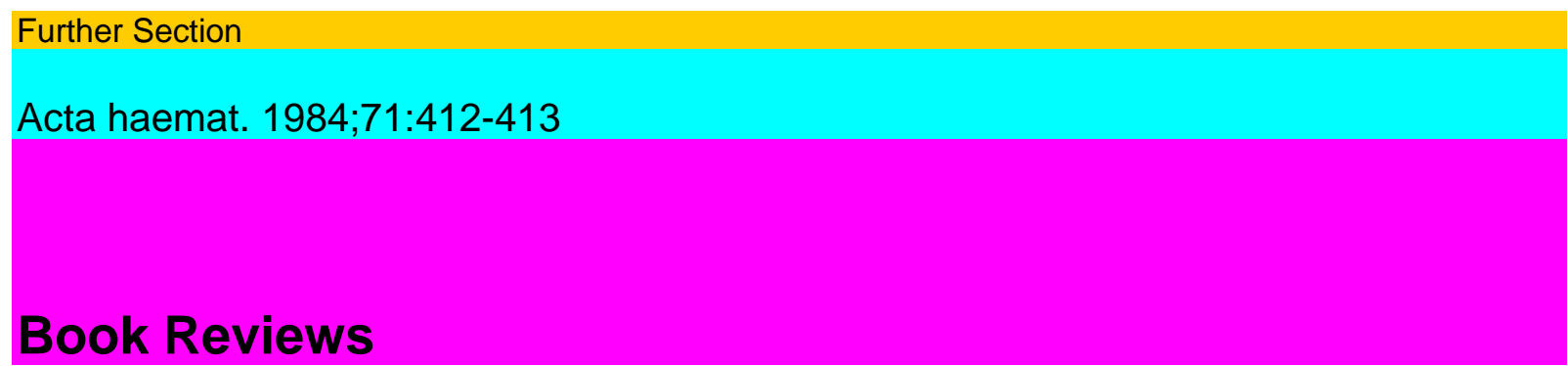

Robert McMillan Immune Cytopenias

Churchill Livingstone, London 1983 IX + 223 pp., E34.00 ISBN 0-443-08228-6

This book addresses mainly researchers working with immunohematological laboratory methods. It deals primarily with methods for the investigation of immune thrombocytopenias. Only one chapter is devoted to the serology of erythrocytes; a few chapters are concerned with methods of assessing immune neutropenias. The 12 articles, contributed by a range of internationally acknowledged experts, are well matched and very well written. All the contributions follow the same pattern: a brief outline of the principle of the method(s); a detailed, very accurate step-wise description of the procedure (including the reagents and materials); problems and limitations of the method(s); report and discussion of own results and of findings published in the literature. The latter, brief, part always indicates the fields of application and the significance of each test. The first chapter (L.D. Petz, D.R. Branch) discusses the evaluation of autoimmune hemolytic anemias. Besides the routine methods, the authors accurately and clearly describe the procedure to be followed in case of complex serological problems. The second chapter (T. J. Kunicki, R.H. Aster) treats a small spectrum of tests for the detection of throm-bocyte-reactive antibodies (51Cr release, platelet suspension immunofluorescence test, RIA for platelet-associated IgG, platelet aggregation). Müller-Eck-hardt et al. discuss the RIA antiglobulin test and its application in cases with immune thrombocytopenias and warm autoimmune hemolytic anemias. Boxer et al. describe the 125I staphylococcus protein A test for the detection of IgG on thrombocytes (direct and indirect) and neutrophils (indirect). C.P. Engelfriet's group describe their thrombocyte fluorescence test following fixation in p-formaldehyde and its application for the assessment of immune thrombocytopenias and neutropenias. J.D. Tamerius and P. Tani of the Scripps, La Jolla, Calif, describe a new ELISA technique thrombocyte compatibility testing. The following chapters are devoted to immunodiffusion

and nephelometry (B.S. Morse et al.), a Fab-anti-Fab test (D. Mason, R. McMillan), the quantitative anti-globulin consumption test (W.F. Rosse), a radioim-munometric test system (J.G. Kelton et al.) and a test system with monoclonal antibodies. These latter tests all aim at the quantitative determination of surface IgG, are relatively time-consuming and therefore mostly tailored for research work. J. Gmür, Zurich

J.D. Watson

Cold Spring Harbor Symposia on Quantitative

Biology, vol. 47

Structures of DNA, Part I + II

Cold Spring Harbor, New York 1983 XXI -I- 575/XV + 1234 pp.; US\$ 168.00 ISBN 0-87969046-1

The structure of DNA, the central information in each cell, was first described by Watson and Crick in 1953 as a simple double helix. Now, 30 years later, it is evident that the most prominent right handed B-form of the double helix represents only one of several configurations which are 
in a dynamic equilibrium: the DNA double helix can be undercoiled or overcoiled, or it can be left turned or right turned.

Why may changes of DNA structure be important for a cell? Consider that only a small part of the genetic information of a cell codes for proteins. In a multicellular organism different cells need different proteins for their architecture and function. Thus each type of cell uses a different subset of genes: expression of genes has to occur in a regulated fashion. Besides the already known regulatory sequences upstream from genes, the local conformation of DNA surrounding genes might tell whether a gene has to be transcribed or has to be silent. Since DNA conformation can vary, subtle changes of DNA structure probably in connection with other factors like DNA binding proteins may represent information in genetic material leading to regulation of gene expression.

The collected papers published in the two volumes of the 47th Cold Spring Harbor Meeting document in an impressive way the analysis of DNA structures and their consequences on gene expression. More than 130 articles written by leading

Book Reviews

413

groups in this field describe conformation analysis, modification, chemical synthesis, replication and recombination of DNA, DNA-protein interactions, the organization of genes and their regulation by surrounding DNA sequences.

These high-standard articles reporting on recent progress on DNA structures and providing insight into different mechanisms of gene regulation are not only relevant to newcomers but are also most stimu lating for every scientist already involved in the fasci nating field of gene expression. J. Stalder, Bern of the fact that about one-fourth of the volume is occupied by original papers from one centre, the impression of group promotion is hard to avoid.

It is regrettable that the cover of the volume does not indicate the type of the book. Late appearance and insufficient editing make these proceedings of little value for general practitioners and specialists. Experts in the field of thrombosis and vascular research will have already found the relevant new findings in specialized journals. E. A. Loeliger, Leiden

\section{A. Strano}

Advances in Experimental Medicine

and Biology, vol. 164

Thrombosis and Cardiovascular Diseases

Plenum Press, New York 1984 XI+ 426 pp.; US\$59.50 ISBN 0-306-41261-6

Since preparations of the publication of the proceedings of the Second European Symposium on Thrombosis and Cardiovascular Disease took more than 3 years, and since the literature referred to by the contributors (exclusively European) has not been updated, the volume is of historical rather than current interest.

The contributions vary greatly in quality, from excellent surveys to insufficiently edited original papers. The grouping of contributions into 8 sub-sections is quite arbitrary (Thrombosis in Coronary Heart Disease: an Assessment of the Present State by the Working Group of the European Society of Cardiology; Coagulation and Vascular Diseases; Vascular Complications of 
Diabetes Mellitus; Platelet Function and Vascular Diseases; Fibrinolysis and Vascular Diseases; Hypertensive Vascular Disease; Pulmonary Vascular Disease; Haemorheology and Vascular Disease). The combinations of items are not always easy to understand. Some contributions fall outside the scope of a subsection's heading. In view U. Bagge, G.V.R. Born, P. Gaethgens White Blood Cells

Microcirculation-Reviews 1 Nijhoff, The Hague 1982170 pp.; US\$34.50 ISBN 90-247-2681-6 This volume covers a number of phenomena which are essentially related to leucocyte emigration from one compartment into an other, i.e. from the intersinal spaces into the circulation or from the blood into the tissues. Much attention is paid to the com plex interrelationship between microcirculatory function and white blood cell function and flow be haviour. Physical parameters like viscoelastic prop erties, deformability and rheology are related to functional parameters, in particular leucocyte margination, adhesiveness to artificial substrata and endothelial cells, passage through the endothelium, shape changes and locomotion of leucocytes in twoand three-dimensional substrata, microvascular oc clusion by leucocytes and vascular permeability. The main interest of this publication is that these differ ent aspects are presented within one volume. The content of the 23 contributions which usually have a 'Materials and Methods' section is, on the average, limited to 7 typewritten pages. The reader can obtain more detailed information through the references. The index is lacking. H.U. Keller, Bern 